from the activities of our council I could mention the Department of Health and Social Security's grant towards treatment and rehabilitation of alcoholics, and also the Medical Research Council's support of research being carried out at the addiction unit of the Institute of Psychiatry, and also at the University of Glasgow.

There is much to do in terms of education, early detection, and prevention, and communication among the many bodies working in this field is of paramount importance in dealing with a problem of national health which has been so seriously neglected in the past.-I am, etc.,

Dick Caldwell

London $\mathbf{w} .1$

The Medical Council on Airector,

\section{Luteinizing Hormone and Progesterone Levels after Hysterectomy}

SIR,-Removal of the uterus has a profound effect on ovarian function in many lower animals, ${ }^{1}$ suggesting that the uterus secretes a luteolytic substance necessary for normal cyclical activity. The psychological effects of simple hysterectomy in woman also suggests a disturbance of ovarian function, though the available evidence does not support this. ${ }^{2}$ Methods of assessment of ovarian function hitherto employed, such as the appearance of the ovaries at laparotomy, vaginal cytology, temperature charts, and urinary oestrogen and pregnandiol excretion, have been imprecise. We have therefore studied the circulating levels of hormones in women who had undergone hysterectomy with conservation of the ovaries and who presented with psychological and other complaints.

Seven subjects whose ages ranged from 26 to 35 years and who had had a hysterectomy 3 to 42 (mean 19) months previously were studied. In each case the ovaries had been conserved. In none was there evidence of major physical or endocrine disease. Blood was taken on the second, fourth, and sixth day of each week over a period of four weeks and was immediately centrifuged and deep frozen while awaiting assay. All specimens from any one subject were assayed together. Luteinizing hormone (LH) was assayed in all samples by a double antibody radioimmunoassay technique. Progesterone assays (by a competitive proteinbinding technique ${ }^{4}$ were performed only on selected samples chosen either to show the presence of luteal activity after high $\mathrm{LH}$ values such as might be associated with "mid-cycle peaks" or to show the absence of such activity during other phases of the cycle. The results were similar in all seven patients and are shown for one typical patient (see Fig.).

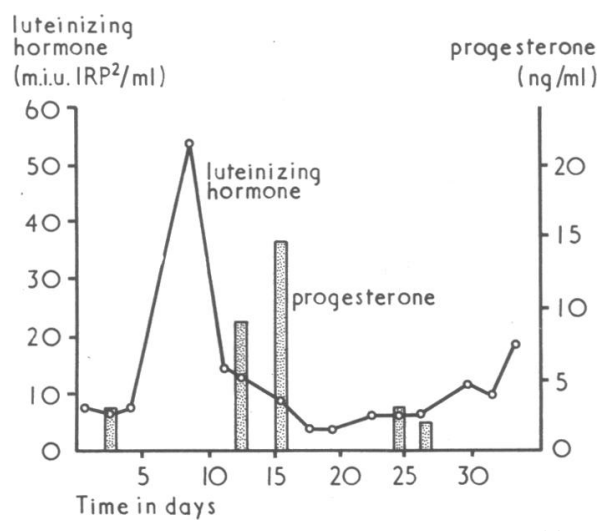

Plasma LH (graph) and plasma progesterone (histogram) levels in typical patient.
LH values showed fluctuation from a basic tonic level to short-lived high values consistent with a mid-cycle peak. The mean LH level preceding the presumptive peak was $13.6 \mathrm{mU}$ 2nd I.R.P./ml (range 4.5-38), the mean "peak" value was $67 \mathrm{mU}$ 2nd I.R.P./ml (range 40-130), and the mean level after the peak was 14.2 $\mathrm{mU}$ 2nd I.R.P./ml (range 4-49). Progesterone values preceding the LH "peaks" were uniformly low, but rose to between 11 and $23 \mathrm{ng} / \mathrm{ml}$ during the presumed lutzal phase in each patient. In two of the patients two $\mathrm{LH}$ "peaks" were observed, one near the beginning and the other towards the end of the period of sampling. The time between these peaks was respectively 23 and 26 days. The mid-cycle $\mathrm{LH}$ peak is of short duration and may easily be missed unless daily specimens are obtain:d. Though our samples were taken at $48-$ or 72 hour intervals, fortunately we were able to show rises in LH levels in all our subjects. Nevertheless, most of the values we have ascribed to the mid-cycle peak were probably related to the days immediately preceding or after the peak itself. This may be the main reason why the mean peak level for our subjects is rather low. Considering the shortcomings of the sampling technioue our $\mathrm{LH}$ and progestrone valuss are surprisingly close to those reported in normal women when samples are collected daily. 45

It seems that in the years immediately after a hysterectomy with preservation of the ovaries cyclical ovarian functioning was maintained in our seven subjects.

We thank Professor M. G. Gelder and Drs. B. M. Mandelbrote and P. C. B. MacKinnon for advice and facilities and Mrs. M. Daly for work in collecting blood samples. The work was supported by a grant from the Medical Research Council (Grant G.970/227C). Miss S. Turnbull was supported by a grant from the Oxford Regional Hospital Board.-We are, etc.,

Depa-tment of Psychiatry,

P. J. V. BEUMONT Groote Schuur Hospital,

University of Cape Town South Africa

P. J. CARR

D. H. RICHARDS

Department of Psychiatry,

S. TuRnBulL

University of Oxford,

Oxford 1 Bradbury, J. T., Brown, W. E., and Gray, L. A., 2 Beavis, E. L. G., Brown, J. B., and Smith, of the British Empire, 1969, 76. 969.

3 Midgley, A. R., Jnr., Endocrinology, 1966, 79. 10 Johansion,
61.592.

61.592 . A R Clinical Endocrinology and Metabolism, 28, 1699.

\section{Estimating Fibrin Products in Urine}

SIR,-The immunochemical method of estimating F-R antigen in urine based on the tanned red cell inhibition technique is not only tedious, because urine concentration is required, but also expensive. We have therefore used a method based on precipitation of fibrin from urine with protamine sulphate.

To $2.0 \mathrm{ml}$ clean unconcentrated urine from a 24-hour collection in thymol preservative is added $3.0 \mathrm{ml} 0.9 \%$ saline and then $0.5 \mathrm{ml} 1 \%$ protamine sulphate. After 24 hours the precipitate is spun down and redissolved in $2.0 \mathrm{ml} 40 \%$ urea in $0.2 \mathrm{~N}$ sodium hydroxide $\mathrm{pH} 7$ and the optical density read at $280 \mathrm{mU}$ in a spectrophotometer. The result is read as fibrin (milligrams per $\mathrm{ml}$ ) from a standard curve.
The figure shows that there is a good relation $(r=0.7)$ between the immunological method and the protamine sulphate (PS)

Relation between $F-R$ antigen in urine and P.S precipitated urinary fibrin

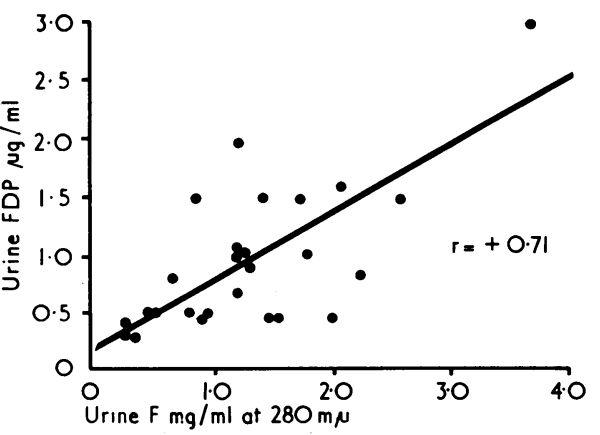

precipitation technique. The discrepancy in the actual quantitation is yet to be explained. Nevertheless, the results indicate that this is much simpler method for estimation of fibrin products in urine.-We are, etc.

E. N. WARDLE

J. Marshall

C. Curtann

Royal Victoria Infirmary,
Newcastle upon Tyne

\section{Dietary Fibre and Calcium Metabolism}

SIR,-Dr. J. K. Anand (14 October, p. 112) queries the effect of the phytate content of additional dietary fibre on calcium metabolism. Mr. N. S. Painter and his colleagues (15 April, p. 137) recommend the use of All-Bran, Weetabix, porridge, wholemeal (not brown) bread, and two teaspoons of unprocessed bran (which contains the germ naturally present) three times a day, to be increased after two weeks if necessary. This quantity, according to the size of teaspoon used, gives $20-30 \mathrm{~g}$ bran a day.

The average phytate phosphorus content of mill-bran is approximately $1 \% .1$ Each millimole of phytic acid, containing $186 \mathrm{mg}$ of phosphorus, requires $240 \mathrm{mg}$ of calcium for neutralization; $30 \mathrm{~g}$ bran containing $1 \%$ phytate would require $387 \mathrm{mg} \mathrm{Ca}$ for neutralization. This quantity added to the recommended intake of $500 \mathrm{mg} \mathrm{Ca} \mathrm{a} \mathrm{day}{ }^{2}$ would give a total well within the average national intake of over $1 \mathrm{~g} \mathrm{Ca}$ a day for the past seven years ${ }^{3}$ and would therefore presumably be safe. But if true wholemeal bread not fortified with creta praeparata and other foods with a high percentage of phytic acid phosphorus are used the safety limit may be exceeded. A better recommendation when bran is prescribed would be to use brown or white bread-lower in phytate content but higher in calcium content because of fortification.

A further factor which may need to be considered is the reduced fermentation time in modern bread-making processes, which limits the action of phytase in flour used. There may certainly be a danger of deficiency of calcium if bran is added to diets of reduced calorie value for treatment of obesity, when the quantities of the main calcium-containing foods (milk, cheese, and fortified bread) are considerably reduced. In such cases an additional source of dietary calcium of comparatively low calorie content 
-for example, skimmed milk powder-may be necessary within or in excess of the stated calorie value of the diet.-I am, etc.,

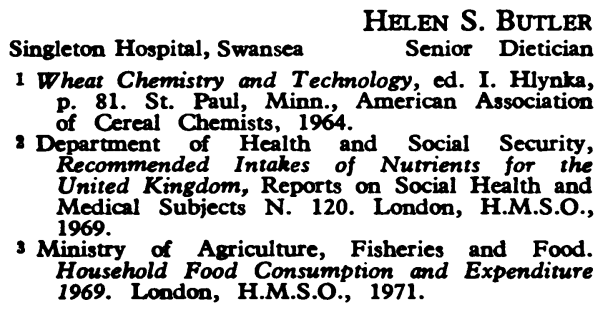

Undergraduate Curriculum

SIR,-Dr. G. E. Crawford's letter (14 October, p. 116) indicates that some people may be under the misapprehension that a main objective of departments of general practice is to influence undergraduate students to become general practitioners.

The principal objective is to broaden an undergraduate's experience of medicine and to let him see at first hand clinical situations which cannot be presented to him in hospital. It is true that in gathering that experience the student may come to believe that general practice is an attractive career. Such a judgement would surely be fortuitous. Training for general practice per se is, as Dr. Crawford's letter states, a postgraduate subject.

I know of no department of general practice that is not concerned with research in and for general practice.-I am, etc.,

Manchester

H. W. K. ACHESON

\section{The Porn Industry}

SIR,-Congratulations on your leading article, "The Porn Industry" (30 September, p. 779). The kind of common sense (and sometimes the humour) that is expressed in your leading articles is something for which I envy British doctors.-I am, etc.,

Munich, Germany

R. WITZMaNN

\section{Heart Failure and Neonatal Hypocalcaemia}

SIR,-The interesting association of heart failure and neonatal hypocalcaemia described by Drs. O. Troughton and S. P. Singh (14 October, p. 76) raises some important points. Some of the earlier reports ${ }^{2}$ of oedema in association with neonatal tetany described its occurrence in the first few days of life. Many of the babies were very ill and diverse factors probably accounted for both the hypocalcaemia and the oedema.

In a recent study ${ }^{3}$ of hypocalcaemic tetany in bottle-fed babies occurring 5-11 days after birth 6 out of 18 babies had bilateral pitting oedema of the feet in the absence of other features of heart failure. The oedema was associated with dilutional hyponatraemia and there was probably an increase in total body water. It was suggested that the high sodium load of the cow's milk diet together with a transient functional immaturity of the kidneys were aetiological factors. Though Drs. Troughton and Singh do not state the type of milk their babies were receiving it is unlikely that the diet was of aetiological significance in the development of oedema, as this sign developed within 48 . hours of birth in several of the babies.

Unless it is appreciated that oedema in association with neonatal hypocalcaemia is not uncommon there is the danger that heart failure will be over-diagnosed. Many of these babies will also have hypomagnesaemia. Under these circumstances I would question the safety of digoxin therapy. Though the role of potassium deficiency in producing digitalis toxicity has been appreciated for many years, comparatively little is known about the effects of magnesium deficiency on the tolerance to digitalis in man. It has been shown in animals that acute depletion of serum magnesium decreases the dose of acetylstrophanthidin needed to produce toxic arrhythmias, ${ }^{4}$ and chronic depletion of magnesium prolongs the duration of digitalis toxicity. ${ }^{5}$ Magnesium-deficient mice given ${ }^{3} \mathrm{H}$-digoxin by the intraperitoneal route have higher myocardial and plasma levels of ${ }^{3} \mathrm{H}$-digoxin after one hour than control mice. ${ }^{6}$ Until more is known about digitalis therapy in the face of magnesium deficiency I would suggest that when the diagnosis of heart failure is open to doubt digoxin should be withheld and a short-acting diuretic be given in addition to calcium and magnesium supplements. In those babies who are obviously in heart failure parenteral magnesium sulphate should be given prior to digitalization.-I am, etc.,

St. Mary's Hospital,

Malcolm L. Chiswick Manchester 1 Kehrer, E., Archiv für Gynähologie, 1913, 99, 372. 46, 549 .

3 Chiswick, M. L., British Medical fournal, 1971,

4eller, R. H., et al., American Heart Foumal, $1970,79,57$.

Kleiger, R. B., Seta, K., Vitale, J. J., and Lown, B., American foumal of Cardiology, 1966, 17,

6 Goldman, R. H., Kleiger, R. E., Schweizer, E., and Harrison, D. C., Proceedings of the Sociery 136, 747 .

\section{Dentist's Libel Action}

SIR,-I am most grateful to you for reporting (4 November, p. 308) my evidence in this regrettable libel action so fully and so accurately, making my position clear. Your report, however, contains one small error. When I referred to the Birmingham team's measuring device as being so sensitive that it might easily have shown exactly the same changes with a person snoring in bed at night, I was referring not to the E.E.G., as your report seems to suggest, but to the device used for detecting respiratory obstruction.

Another tiny slip, perhaps due to an error in the transcript of my evidence, is to be found near the foot of your first column, where you quote me as having said that there was rapid recovery, but that the patient had to be kept hot for an hour or more. What actually I said I cannot remember, but it was certainly not hot.-I am, etc.,

Salisbury,

J. G. BOURNE

Wilts

**The phrase "the patient has to be kept hot" was indeed in the official transcript of Dr. Bourne's evidence.-ED., B.M.J.

\section{Leucocytes in the Faeces}

SIR,-I feel that your leading article on leucocytes in the faeces (14 October, p. 62) should not pass without comment. Reference was made to the investigations of J. C Harris and others, who administered intestinal pathogens (Salmonella typhi and Shigella species) to volunteers.

From their article one finds that the volunteers were "informed adult inmates of the Maryland House of Correction." I expected that a journal of the B.M.f.'s reputation would discuss the ethics of this study as well as applaud the results.-I am, etc.,

ARTHUR RUSHTON

Aberdeen Royal Infirmary,

Aberdeen

1 Harris. J. C., DuPont, H. L., and Hornick, R. B., Annals of Internal Medicine, 1972, 76, 697.

\section{Multiple Factors in Leukaemogenesis}

SIR,-The work of I. D. Bross and N. Natarajan, ${ }^{1}$ quoted in your leading article (21 October, p. 128), raises some disturbing thoughts in the preventive medicine sector. Could it be that the leukaemogenic potential of the attenuated (vaccine) measles virus is in the same class as that of its rogue (wild) cousin? Is there any likelihood that early immunization against measles in close temporal association with $x$-irradiation would increase the risks of leukaemogenesis?

Perhaps these are unworthy thoughts. Perhaps someone has already studied and dismissed these possibilities. If such is the case I would like to be reassured. Otherwise it may be desirable to withhold immunization against measles, for example, from children who received radiation antenatally and to be even more reluctant to $x$-ray children who have been immunized against measles in the recent past.-I am, etc.,

Ilford, Essex

J. K. ANAND

1 Bross, I. D., and Natarajan, N., New England Fournal of Medicine, 1972, 287, 107.

\section{Gastric Acid Secretion in}

Chronic Renal Failure

SIR,-I was interested to read the paper by Dr. P. S. Ventkateswaran and others on gastric acid secretion in chronic renal failure (7 October, p. 22), and am grateful to them for pointing out the distinction in the paper of Fillastre et al. ${ }^{1}$ between volume of secretion and hydrogen ion concentration. However, some of the statements Dr. Ventkateswaran and his colleagues make need clarification.

They say that there is an increased incidence of peptic ulceration in patients with chronic renal failure. Certainly the proportion seems to be high, but in order to say it is increased the incidence must be related either to a random sample of the population of equivalent age and sex distribution or to a similar group of patients with chronic severe illness but not renal disease. In addition, having stressed that gastric secretion is different in males and females, they do not say whether the control group and renal failure group were matched for age and sex.

The third point is the interesting effect of dialysis. Again we may ask whether the 